\title{
Hypoxemia and Cytokine Storm in COVID-19: Clinical Implications
}

\author{
Calixto Machado-Curbelo MD PhD FAAN and Alina González-Quevedo MD PhD
}

\begin{abstract}
One of the most dreadful complications that can occur during the course of COVID-19 is the cytokine storm-also known as cytokine release syndrome-a form of systemic inflammatory response syndrome triggered by SARS-CoV-2 infection.
\end{abstract}

The cytokine storm is an activation cascade of auto-amplifying cytokines, which leads to excessive activation of immune cells and generation of pro-inflammatory cytokines. It occurs when large numbers of white blood cells are activated and release inflammatory cytokines, in turn activating even more white blood cells, finally resulting in an exaggerated pro-inflammatory-mediated response and ineffective antiinflammatory control, leading to tissue damage, multiorgan failure, acute respiratory distress syndrome and death. Although cytokine storm pathogenesis is multifactorial, we hypothesize there is a close association between hypoxemia and cytokine storms in COVID-19, although it is difficult to establish the direction of this relationship. Most probably they coexist and, given enough time, one triggers the other in a chain reaction. Careful analysis of the day-to-day clinical evolution of COVID-19 indicates that there are short and slight periods of hypoxemia (confirmed by pulse oximetry and

\section{INTRODUCTION}

One of the worst complications during the clinical course of COVID-19 is the cytokine storm (CS), also known as cytokine release syndrome, a type of systemic inflammatory response syndrome that can be triggered by a variety of factors, including infections and certain drugs. In COVID-19, CS occurs when large numbers of white blood cells are activated and release inflammatory cytokines, in turn activating even more white blood cells, and is finally associated with exaggerated pro-inflammatory-mediated response and ineffective control by the anti-inflammatory system, leading to tissue damage, multiorgan failure, acute respiratory distress syndrome (ARDS) and death.[1]

Although CS pathogenesis is multifactorial, in this essay we hypothesize on hypoxemia as a main CS trigger in COVID-19. The mechanisms of lung damage and hypoxemia in COVID-19 include

\section{IMPORTANCE}

We discuss hypotheses positing a close interrelationship between hypoxemia and cytokine storm in COVID-19, as well as the importance of preventing intermittent periods of hypoxemia using continuous positive airway pressure in the early clinical stages of the disease to avert hypoxemia's triggering effect for cytokine storm and development of acute respiratory distress syndrome, organ failure and death.
}

arterial gasometry), even on the day of the onset of persistent cough and/or shortness of breath.

We propose the use of continuous positive airway pressure in early stages of COVID-19, at the onset of respiratory symptoms. This non-invasive ventilation method may be useful in individualized treatments to prevent early hypoxemia in COVID-19 patients and thus avoid triggering a cytokine storm.

We believe such an approach is relevant everywhere, and in Cuba in particular, since the country has initiated national production of mechanical ventilation systems, including non-invasive ventilators. Moreover, as Cuba's COVID-19 protocols ensure early patient admission to isolation centers or hospitals, clinicians can prescribe the early use of continuous positive airway pressure as soon as respiratory symptoms begin, averting early hypoxemia and its triggering effect on cytokine storm development, and consequently, avoiding acute respiratory distress syndrome, multi-organ failure, and death.

KEYWORDS COVID-19, SARS-CoV-2, cytokine release syndrome, respiratory distress syndrome, noninvasive ventilation, continuous positive airway pressure, Cuba

ventilation/perfusion mismatch, loss of hypoxic vasoconstriction and increased coagulopathy.[2,3]

Although COVID-19's clinical progression varies from patient to patient, ranging from asymptomatic to severe disease,[4] the disease's day-to-day clinical evolution can be described generally as in Table 1.[4-6]

COVID-19 presents mildly in most patients, commonly beginning with fever followed by a dry cough that dissipates without medical intervention, and flu-like symptoms like headache, malaise and muscle pain, which may develop early in symptomatic persons. Mild cases have been associated mainly with younger patients, but in some cases, these symptoms may progress to shortness of breath that usually starts within a seven-day period before appearance of a more severe form of the disease.[5,6] While many patients recover in about a week, a significant number enter a very nasty second week of illness. Usually, after onset of initial symptoms, the course of the disease plateaus and patients may even improve. This improvement is sometimes followed by an additional round of worsening symptoms. According to the Cuban Protocol for COVID-19,[4] severe complications, like ARDS, most often occur after the second week of clinical evolution.[4-6]

Hence, in considering a careful analysis of the day-to-day clinical evolution, short and slight periods of hypoxemia start even at the first manifestation of persistent cough and/or shortness of breath, as reported by authors using pulse oximetry and arterial gasometry.[6,7] Afterwards, breathing difficulty might worsen, leading to augmented periods of hypoxemia.[8] Persistent cough, 
Table 1: Frequent timeline of symptoms in COVID-19 patients, day-by-day*

\begin{tabular}{|c|c|}
\hline Day 1 & Fever, fatigue, muscle pain and dry cough \\
\hline Day $2-4$ & Fever and cough persist \\
\hline Day 5 & Breathing difficulty begins \\
\hline Day 6 & Breathing difficulty, fever and cough \\
\hline Day 7 & $\begin{array}{l}\text { Patients who still have trouble breathing are admitted to } \\
\text { the hospital }\end{array}$ \\
\hline Day 8 & Acute respiratory distress syndrome (ARDS) may develop \\
\hline Day 10 & If breathing worsens, patient is admitted to the ICU \\
\hline Day 12 & Fever ends in patients who are improving \\
\hline Day 13-14 & Shortness of breath stops in patients who are improving \\
\hline Day 18.5 & $\begin{array}{l}\text { In the worst-affected patients, ARDS worsens and death } \\
\text { occurs } \\
\text { Illness ends in patients who are improving }\end{array}$ \\
\hline
\end{tabular}

*Although the clinical picture of COVID-19 patients can vary from asymptomatic to severe disease, in most patients the day-by-day clinical evolution can be described as in this table.[4]

Note that the first respiratory symptoms begin on the first day of the clinical evolution. Acute respiratory distress syndrome occurs approximately at day 8 .

among other symptoms, is considered a strong predictor of poor progression.[9] Nonetheless, some asymptomatic patients present pulmonary lesions in computerized tomography (CT) scans, and therefore the Cuban Protocol proposes early imaging studies, even in patients who remain asymptomatic.[4]

Oxygen saturation $\left(\mathrm{SpO}_{2}\right)$ measured by pulse oximetry may be useful in estimating blood oxygen saturation, at onset of first respiratory symptoms, although $\mathrm{SpO}_{2}$ should be carefully interpreted in COVID-19. The sigmoid-shaped oxyhemoglobin dissociation curve shifts to the left, due to induced respiratory alkalosis, characterized by a drop in carbon dioxide partial pressure in arterial blood $\left(\mathrm{PaCO}_{2}\right)$, because of hypoxemia-driven tachypnea and hyperpnea. During hypocapnic periods, the affinity of hemoglobin for oxygen, and thus oxygen saturation, rises for a specified degree of partial pressure of oxygen $\left(\mathrm{PaO}_{2}\right)$, explaining why $\mathrm{SpO}_{2}$ can be well preserved despite profoundly low $\mathrm{PaO}_{2}$, suggesting the need to monitor blood gases by arterial gasometry.[10]

Therefore, it is important to note that acute lung injury, hypoxemia, systemic inflammatory response syndrome and ARDS can occur after SARS-CoV-2 infection. Hence, CS in COVID-19 patients is intrinsically involved in aggravating symptoms and spurring on disease progression, and denotes a key factor contributing to ARDS and death.[11]

Many therapeutic strategies have been used to treat COVID-19 patients, including steroids, non-steroidal anti-inflammatory drugs, antiviral drugs, etc.[12] Moreover, current treatment approaches under investigation are targeting the overactive cytokine response with anti-cytokine therapies or immunomodulators, but these must be balanced by maintaining adequate inflammatory response for pathogen clearance.[13]

Two main strategies might be followed to prevent CS onset in COVID-19.[14] The first is development of new drugs that inhibit pathways in the cascade of uncontrolled cytokine production (for example, the Cuban Protocol for COVID-19 uses Jusvinza and Itolizumab to stop hyperinflammatory reactions in COVID-19).[4] The second is early prevention of hypoxemia.
Here, we delve into the second strategy, since within the CS multifactorial pathogenesis, our objective is to address our hypothesis on the close interrelationship between hypoxemia and CS in COVID-19 patients, and highlight the importance of preventing intermittent periods of hypoxemia in the disease's early clinical stages.[15-18]

\section{EARLY PREVENTION OF HYPOXEMIA TO AVERT CYTOKINE STORM}

Cytokine storm and hypoxemia The immune system is a complex mechanism capable of responding to innumerable pathogens. Normal antiviral immune response includes activation of the immune system's inflammatory pathways. A crucial part of this inflammatory process includes cytokines and chemokines produced by several cells of the innate immune system (macrophages, dendritic cells, natural killer cells), and adaptive T and B lymphocytes.[19]

CS is an activation cascade of auto-amplifying cytokine production due to unregulated host immune response to different causes, and is therefore recognized as a systemic inflammatory response to drugs and infections, which leads to excessive activation of immune cells and generates proinflammatory cytokines. The term CS calls up images of an outof-control inflammatory response and an immune system run amok.[19,20]

CS after SARS-CoV-2 infection is considered to be an overreaction of the body's immune system, which releases immune messengers-cytokines-into the bloodstream out of proportion to the threat or long after the virus is no longer a threat. When this happens, the immune system attacks the body's own tissues, causing significant harm.[19]

Moreover, inflammation during CS induces a defective procoagulant-anticoagulant balance predisposing patients to develop microthrombosis and disseminated intravascular coagulation. This requires use of anticoagulants, particularly heparin, which has been recommended by expert consensus for patients with severe COVID-19.[21] This exaggerated inflammatory response may damage the liver, blood vessels, kidneys and lungs, and increase the formation of blood clots throughout the body, leading to multiorgan failure. Ultimately, CS may cause more harm than SARS-CoV-2 itself.[22]

The immune responses induced by SARS-CoV-2 infection consist of two clinical phases. During early incubation and nonsevere stages, a specific adaptive immune response is initiated to exterminate the virus and halt disease progression. The second phase is often related to increased severity of the disease and is characterized by potentially deadly lung inflammation and the advent of systemic symptoms with anomalous and unrestrained production of cytokines, known as CS.[19]

Hypoxia is a common feature of SARS-CoV-2 infection, impacting COVID-19 clinical evolution, including induction

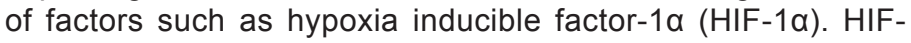
$1 \alpha$ is activated during the immune response and induces pro-inflammatory cytokine production through immune cells, supporting our hypothesis that hypoxemia triggers CS cascade. $[19,20]$ 
During the early stages of SARS-CoV-2 infection, innate immune response leads to hypoxia at inflammation sites. Hypoxia is a microenvironmental feature of chronically inflamed tissues that can impact inflammatory process progression in several ways. HIF-1 $1 \alpha$ and nuclear factor-kB (NF-kB) are two hypoxiaresponsive transcription factors which, in addition to controlling independent cohorts of adaptive and inflammatory genes, are highly interdependent. HIF-1a regulates significant cellular processes (cell proliferation, metabolism and angiogenesis) and induces pro-inflammatory cytokine production through immune cells including IL-6 and tumor necrosis factor-alpha (TNF- $\alpha$ ), in addition to activating the signal transducer and activator of the transcription 3 (STAT3) pathway.[15,23-25] Figure 1 summarizes our hypothesized relationship between the evolution of hypoxemia and cytokine storm.

SARS-CoV-2 binds and infects cells through the angiotensinconverting enzyme 2 (ACE2) receptor, widely dispersed through mammalian tissue. The two types of ACE receptors (ACE1 and ACE2) act as opposites in the pulmonary endothelium: ACE2 functions as a vasodepressor whereas ACE1 is a vasoconstrictor. Under normal physiological conditions, ACE1 and ACE2 exist in a dynamic equilibrium. However, in hypoxemic conditions, like those found in SARS-CoV-2-infected patients, ACE1 is upregulated by HIF-1a, while the expression of ACE2 is regulated bidirectionally, increased during the early stages of hypoxemia and decreased to near-baseline levels during later disease stages.[3,24,26]

The lungs seem to be the main target, although other organs with high ACE2 expression-such as the intestines, heart,

Figure 1: Proposed hypoxemia and cytokine storm relationship in COVID-19 patients

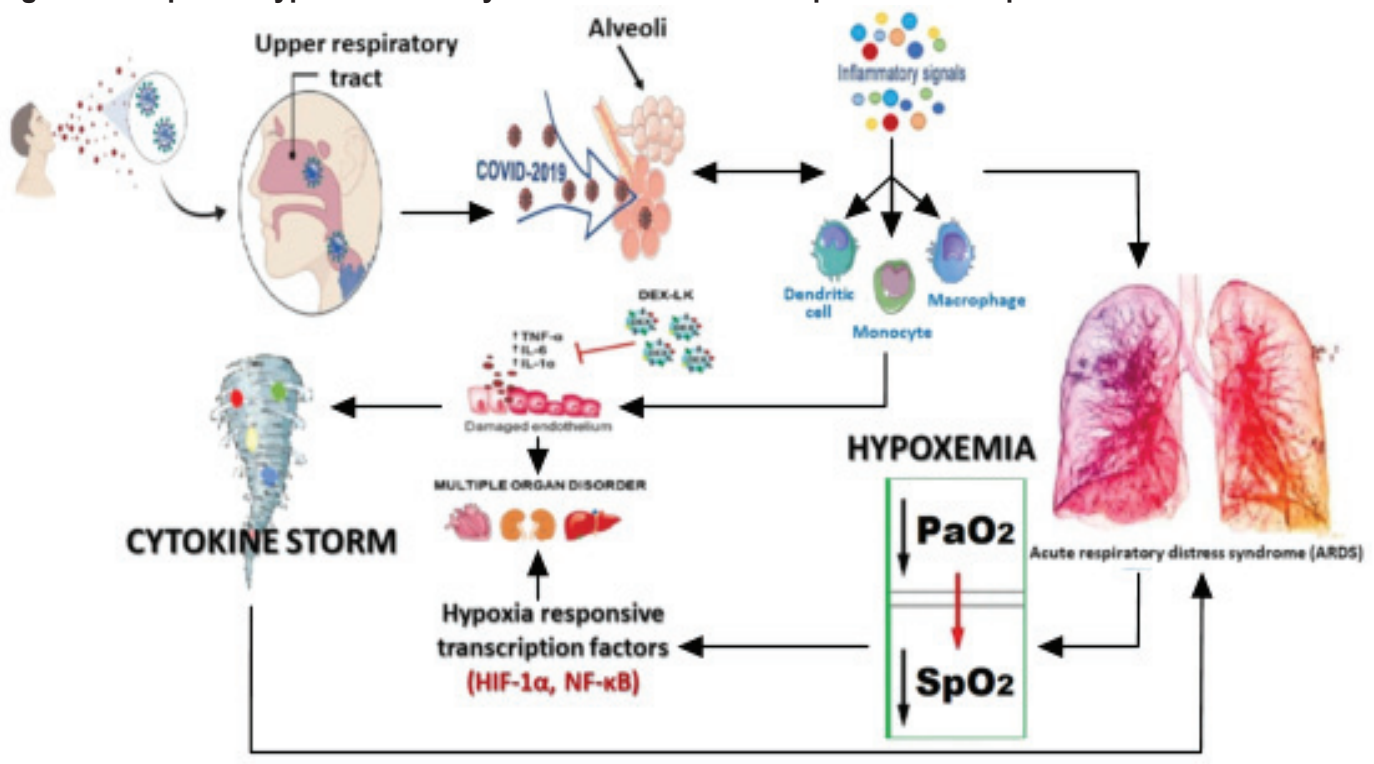

We hypothesized there is a close association between hypoxemia and cytokine storm in COVID-19 patients, but it is difficult to establish the direction of this relationship. Most probably they coexist, and in time, one triggers the other as in a chain reaction, favored by hypoxia-responsive transcription factors HIF-1 $\alpha$, and NF-KB. There are multiple cytokines involved in the cytokine storm. In this figure, only some important cytokines are presented: IL-1 $\alpha$, and IL-6, and TNF- $\alpha$.

$\mathrm{PaO}^{2}$ : Partial pressure of arterial oxygen; $\mathrm{SpO}^{2}$ : Oxygen saturation measured by pulse oxymetry

(This figure shows some elements taken from Castelli V, Cimini A and Ferri C (2020) Cytokine Storm in COVID-19: "When You Come Out of the Storm, You Won't Be the Same Person Who Walked in”. Front. Immunol. 11:2132. doi: 10.3389/ fimmu.2020.02132) brain and kidneys-may also be vulnerable.[19] The first mmune cell types to find viral antigens in the respiratory tract phagocytosis. Damaged cells in the lungs provoke a sturdy ate immune response that appears to be mediated mainly by pro-inflammatory macrophages and granulocytes, which are

Another conceivable explanation for such severe hypoxemia occurring in otherwise compliant lungs is hypoxic vasoconstriction and loss of perfusion regulation. Several authors contend that anse pulmonary microvascular thrombosis might be the cause of in early SARS-CoV-2-induced pneumonia. Histologic complement-mediated thrombotic microvascular injury happens severe SARS-CoV-2 infection, with continuous activation of anticoagulants, specifically low molecular-weight heparin, be

COVID-19 respiratory distress pathophysiology has been described as inflammation-induced pulmonary vasculitis, causing varying degrees of lung collapse secondary to edema and mbosis, which is characterized by bilateral ground-glass opacities on CT scan, resulting in ventilation-perfusion ratio (V/Q)

Cytokine-mediated lung endothelial and epithelial cell injury may damage the integrity of the blood-air barrier, thus promoting vascular permeability in addition to alveolar edema, infiltration by inflammatory cells, and hypoxemia. In COVID-19, as tissue breaks down, the walls of the lungs' tiny air sacs become leaky and fill with fluid, causing pneumonia and starving the blood of oxygen. These phenomena also lead to a lack of oxygen supply in tissues and organs due to blood hypoperfusion. Moreover, proinflammatory cytokines overwhelm mitochondrial oxygen utilization, resulting in a change of metabolic pathway from oxidative phosphorylation to glycolysis, consequently triggering cells to change their mode of metabolism to glycolytic or anaerobic.[29]

Experimental rat models demonstrated that in hypoxemic microenvironmental conditions favored by enhanced HIF-1 $\alpha$ activity, suppression of HIF-1 transcription or inhibition of its activity are perhaps effective in ameliorating inflammation caused by viral infection, such as in the lungs of COVID-19 patients.[24] 
Systemic intermittent hypoxia is a life-threatening condition that happens in many diseases and situations, including chronic obstructive pulmonary disease, congestive heart failure and obstructive sleep apnea syndrome, all of which may coexist with SARS-CoV-2 infection in some patients.[30]

As previously discussed, hypoxemia can appear in early stages of COVID-19. Hypoxia is a common feature in inflammatory sites, which can eventually result in hypoxemia, leading in turn to induction of factors like HIF-1a. HIF-1a regulates important cellular processes, including cell proliferation, metabolism and angiogenesis. HIF-1 $\alpha$ is activated during the immune response and plays an important role at the inflammation site by inducing proinflammatory cytokine production, leading to CS.[10,20,23-25,30] All the evidence connecting hypoxemia with CS highlights the importance of avoiding the former in COVID-19 patients as early as possible, to prevent development of the latter, by using noninvasive ventilation (NIV), as described in the following section.

Invasive or non-invasive ventilation in COVID-19 patients Over the past decade, NIV use has gained popularity in acute manifestations of chronic obstructive pulmonary disease (COPD). [31] Treatment for severe respiratory failure in COVID-19 patients has included early intubation and invasive ventilation, as this was deemed preferable and more effective than non-invasive options. Nevertheless, evolving evidence has shown that NIV may have a more significant and helpful role than first thought. NIV avoids the need for sedation, allows easier communication with patients and requires less intensive nursing care.[31]

There are three types of NIV: high-flow nasal oxygen (HFNO), BiPAP (bi-level positive airway pressure) and continuous positive airway pressure (CPAP).[31]

High-flow nasal oxygen HFNO therapy, administered through nasal cannulae, is a technique whereby heated and humidified oxygen is delivered at high flow rates. Such rates generate low levels of positive pressure in the upper airways, and the fraction of inspired oxygen $\left(\mathrm{FIO}_{2}\right)$ levels can be attuned by varying the oxygen amount in the driving gas. High flow rates may also reduce physiological dead space by flushing expired $\mathrm{CO}_{2}$ from the upper airway, a process that may possibly explain the observed decline in respiration. In patients with acute respiratory failure, high-flow oxygen has been shown to result in better comfort and oxygenation than standard oxygen therapy delivered through a face mask.[32] This method may be useful to assure oxygenation during the time needed to prepare a ventilator.[4]

The 2012 Berlin definition of ARDS provided validated support for three levels of initial arterial hypoxemia that correlated with mortality in ventilated patients.[32] Since 2015, HFNO has become widely used as effective therapeutic support for ARDS, most recently in patients with severe COVID-19. It is noteworthy that the Berlin criteria propose the use of HFNO to treat ARDS, and not to prevent hypoxemia in the early stages of the disease.[32]

Nonetheless, HFNO use remains controversial in suspected and confirmed severe cases of COVID-19. As a result, the current national guidance in the UK does not recommend HFNO in COVID-19, citing lack of evidence proving its efficacy, high oxygen usage and risk of infection.[33]
Bilevel positive airway pressure BiPAP is commonly used in the care of patients with chronic respiratory disease, so it may be useful in COVID-19 patients. In COVID-19, BiPAP may have clinical use in improving the work of breathing. However, it carries the risk that inappropriate settings may allow the patient to take an excessively large tidal volume causing baro- and volutrauma. BiPAP allows for high driving pressure coupled with low driving pressure. Before commencing BiPAP, the patient must be assessed for pneumothorax, ideally by a chest x-ray or ultrasound. Due to the need for chest auscultation in COVID-19 patients, BiPAP is not recommended as it increases the risk of viral transmission to healthcare personnel.[34]

Continuous positive airway pressure CPAP is a simple and costeffective intervention. Its use has been established for the care of other respiratory disorders but not for COVID-19 respiratory failure. At the beginning of the pandemic, international guidelines, including those from $\mathrm{WHO}$, did not address the use of CPAP in COVID-19 patients, focusing instead on HFNO and invasive mechanical ventilation following intubation. In contrast, the UK National Institute for Health and Care Excellence guidance recommended the use of CPAP on April 9, although admitting evidence was lacking on its effectiveness.[33]

Nowadays, with CPAP equipment improved and commercially available, there is growing indication that it may be advantageous for avoiding hypoxemia in COVID-19 patients and thus halting disease progression, while reducing the need for invasive ventilation.[35,36] Ventilation systems have been developed in Cuba, CPAP among them, with the devices necessary for preventing aerosol dissemination, thus significantly reducing the possibility of contaminating health workers and other patients.[4]

Brusasco has recommended using CPAP in all patients presenting with signs of a severe intrapulmonary shunt $\left(\mathrm{PaO}_{2} / \mathrm{FiO}_{2}<200\right.$ or $\mathrm{PaO}_{2}<60 / \mathrm{mmHg}$ on Ventimask $50 \%$ ) or increased effort in breathing ( $\mathrm{BF}>30 / \mathrm{min}$ or dyspnea) before considering invasive ventilation.[37]

Furthermore, negative results found for CPAP patients are not directly related to its use, as shown by evidence that reports that the failure of CPAP to avert death or invasive mechanical ventilation was related to amplified blood levels of thromboinflammatory and cardiac injury/dysfunction biomarkers occurring in the intensive care unit (ICU).[38]

CPAP is usually initiated at a higher level than normal intrinsic pressure (approximately $5 \mathrm{~cm} \mathrm{H}_{2} \mathrm{O}$ ). For most ARDS patients, it is secondary to conditions that either collapse the alveoli or widen the gap between alveoli and surrounding blood vessels, thereby reducing gaseous exchange. Application of positive end expiratory pressure (PEEP) assists in maintaining patient airway pressure, thus preventing alveolar collapse and, in turn, increasing lung volumes and distending the lungs, reducing distance between alveoli and blood vessels, and improving gaseous exchange.[37] In severe COVID-19, initial CPAP settings have been suggested to begin at $10 \mathrm{~cm} \mathrm{H}_{2} \mathrm{O}$ and $60 \%$ oxygen.[39,40]

Some authors have demonstrated that the use of CPAP through a helmet mask in ARDS has prevented intubation in a significant number of patients,[41] although this methodology is a more complex use of CPAP. 
Nonetheless, an important caveat is the possibility of aerosol dissemination, spreading the virus to health workers and other patients.[41] Two European countries heavily affected by the pandemic, Spain and Italy, tried to quickly develop safe NIV systems to treat COVID-19 patients, and created an emergency CPAP mask. This device has a positive end-expiratory pressure (PEEP) valve and a Venturi connector fitted to a facial snorkel interface.[42,43] Other alternatives have been proposed such as simple face masks, Venturi masks, non-rebreather (NRB) masks, and masks with reservoir bags. It has been argued that CPAP, as non-invasive ventilation (delivered by a mask with air diffusers), has low risk of aerosolization, provided that there is good mask fit. Of course, it is important to follow step-by-step instructions on cleaning CPAP devices and masks.[18,23,43,44] These guidelines for health worker protection are documented in detail in the Cuban Protocol for COVID-19.[4]

Persistent cough and shortness of breath in early COVID-19 stages can lead to periods of hypoxemia and subsequently to CS. This may cause worsening in a substantial proportion of patients over a short period, leakproof clinical states, and lead to death from ARDS. In the case of COVID-19 patients suffering ARDS in ICUs, invasive ventilation is preferred and recommended.[4] Some authors have proposed that CPAP is a reasonable and effective therapeutic strategy that may potentially delay or even avert the need for intubation in many patients.[44]

As has already been discussed, there is a close interrelationship between hypoxemia and CS. CS generates additional hypoxia in tissues and organs, leading to a chain reaction between hypoxemia and CS.[15-18] Hence, our proposal is the use of CPAP as an NIV method, outside the ICU, as early as possible in the disease's clinical evolution, when the first respiratory symptoms begin, to prevent periods of hypoxemia. $[6,7,23]$ In Cuba, particularly, it is possible to use CPAP for these purposes, as COVID-19 protocols assure early admission of patients to isolation centers or hospitals, even when they are still asymptomatic,[4] and moreover, national production of ventilation systems has been initiated, including production of NIV equipment. Hence, clinicians can promptly detect the onset of respiratory symptoms, and are able to prescribe early CPAP use in these patients. This NIV method can be individually adjusted, depending on the intensity and frequency of respiratory symptoms, but it is crucial to consider times when patients are sleeping. According to the Cuban Protocol for COVID-19, the main complications of the disease generally occur after the second week of clinical evolution,[4] so there is time to prevent hypoxemia's triggering of CS.

\section{CONCLUSIONS}

Based on the relationship between hypoxemia and CS, we recommend evaluating the use of CPAP in the early stages of COVID-19 disease, at the onset of first respiratory symptoms (persistent cough and/or shortness of breath) as a personalized treatment to avert hypoxemia in patients evaluated by pulse oximetry or arterial gasometry. This would prevent hypoxemia's triggering effect on CS, thus potentially avoiding ARDS, multiorgan failure and death. - 1 1 -

\section{REFERENCES}

1. Zhang DM, Chen SL. Cytokine storms caused by novel coronavirus 2019 and treatment for cardiac injury. Eur Rev Med Pharmacol Sci. 2020 Dec;24(23):12527-35.

2. Mitchell WB. Thromboinflammation in COVID-19 acute lung injury. Paediatr Respir Rev. 2020 Sep;35:20-4. DOI: 10.1016/j.prrv.2020.06.004 Epub 2020 Jun 11

3. Lang M, Som A, Mendoza DP, Flores EJ, Reid N, Carey D, et al. Hypoxaemia related to COVID-19: vascular and perfusion abnormalities on dual-energy CT. Lancet Infect Dis. 2020 Dec;20(12):1365-6. DOI: https://doi.org/10.1016/ S1473-3099(20)30367-4

4. Ministry of Public Health (CU). Protocolo de Actuación Nacional para la COVID-19 (Versión 1.6) 28 marzo 2021 [Internet]. Havana: Ministry of Public Health (CU); 2021 Mar 28 [cited $2021 \mathrm{Apr}$ 21]. Available at: https://files .sld.cu/editorhome/2021/2003/2028/minis terio-de-salud-publica-protocolo-de-actua cion-nacional-para-la-covid-2019-version -2021-2026-2028-marzo-2021. Spanish.

5. Gautret P, Million M, Jarrot PA, Camoin-Jau L, Colson P, Fenollar F, et al. Natural history of COVID-19 and therapeutic options. Expert Rev Clin Immunol. 2020 Dec;16(12):115984.

6. Teo JTR, Abidin NH, Cheah FC. Severe acute respiratory syndrome-Coronavirus-2 infection: a review of the clinical pathological correlations of Coronavirus disease-19 in children. Malays $\mathrm{J}$ Pathol. 2020 Dec;42(3):349-61.

7. Parasher A. COVID-19: Current understanding of its pathophysiology, clinical presentation and treatment. Postgrad Med J. 2021 May;97(1147):312-20. DOI: 10.1136/postgrad medj-2020-138577
8. Ackermann M, Verleden SE, Kuehnel M, Haverich A, Welte T, Laenger F, et al. Pulmonary vascular endothelialitis, thrombosis, and angiogenesis in Covid-19. N Engl J Med. $2020 \mathrm{Jul}$ 9;383(2):120-8.

9. Saeed $H$, Osama H, Madney YM, Harb HS, Abdelrahman MA, Ehrhardt C, et al. COVID-19; current situation and recommended interventions. Int J Clin Pract [Internet]. 2020 Dec 5 [cited 2021 Apr 20]. Available at: https://doi .org/10.1111/ijcp.13886. Epub ahead of print.

10. Dhont S, Derom E, Van Braeckel E, Depuydt P, Lambrecht BN. The pathophysiology of 'happy' hypoxemia in COVID-19. Respir Res [Internet]. 2020 Jul 28 [cited 2021 Apr 21];21(198). Available at: https://doi.org/10.1186/s12931-020-01 462-5

11. Zhou F, Yu T, Du R, Fan G, Liu Y, Liu Z, et al. Clinical course and risk factors for mortality of adult inpatients with COVID-19 in Wuhan, China: a retrospective cohort study. Lancet. $2020 \mathrm{Mar}$ 28;395(10229):1054-62.

12. Kim P, Read S, Fauci A. Therapy for early COVID-19: a critical need. JAMA [Internet]. 2020 Dec 1 [cited 2021 Apr 22];324(21):2149-50. Available at: https://doi.org/10.1001/jama.2020.22813

13. Jose RJ, Manuel A. COVID-19 cytokine storm: the interplay between inflammation and coagulation. Lancet Respir Med. 2020 Jun;8(6):e46-e47.

14. Tang L, Yin Z, Hu Y, Mei H. Controlling cytokine storm is vital in COVID-19. Front Immunol [Internet]. 2020 Nov 30 [cited 2021 Apr 20];11:570993. Available at: https://www.frontiersin.org/articles/ 10.3389/fimmu.2020.570993/full

15. Jahani M, Dokaneheifard S, Mansouri K. Hypoxia: A key feature of COVID-19 launching activation of HIF-1 and cytokine storm. J Inflamm [Internet]. 2020 Oct 29 [cited 2021 Apr
21];17(33). Available at: https://doi.org/10.1186/ s12950-020-00263-3

16. Signori D, Bellani G, Calcinati S, Grassi A Patroniti N, Foti G. Effect of face mask design and bias flow on rebreathing during noninvasive ventilation. Respir Care. 2019 Jul;64(7):793-800.

17. Jaber S, Bellani G, Blanch L, Demoule A, Esteban A, Gattinoni L, et al. The intensive care medicine research agenda for airways, invasive and noninvasive mechanical ventilation. Intensive Care Med. 2017 Sep;43(9):1352-65.

18. Bellani G, Grasselli G, Cecconi M, Antolini L, Borelli M, De Giacomi F, et al. Noninvasive ventilatory support of COVID-19 patients outside the intensive care units (WARd-COVID). Ann Am Thorac Soc [Internet]. 2021 Jan 4 [cited 2021 Apr 21];18(6):1020-8. Available at: https://doi .org/10.1513/AnnalsATS.202008-10800C

19. De Virgiliis F, Di Giovanni S. Lung innervation in the eye of a cytokine storm: neuroimmune interactions and COVID-19. Nat Rev Neurol [Internet]. 2020 Nov [cited 2021 Apr 21];16(11):645-52. Available at: https://doi.org/10.1038/s41582-020 -0402-y. Epub 2020 Aug 25.

20. Serebrovska ZO, Chong EY, Serebrovska TV, Tumanovska LV. Hypoxia, HIF-1a, and COVID-19: from pathogenic factors to potential therapeutic targets. Acta Pharmacol Sin [Internet]. 2020 [cited 2021 Jul 21];41:1539-46. Available at: https://doi.org/10.1038/s41401-020-00554-8

21. Gozzo L, Viale P, Longo L, Vitale DC, Drago F. The potential role of heparin in patients with COVID-19: beyond the anticoagulant effect. A review. Front Pharmacol [Internet]. 2020 Aug 21 [cited 2021 Apr 23];11:1307. Available at: https:// doi.org/10.3389/fphar.2020.01307

22. Jose RJ, Williams A, Manuel A, Brown JS, Chambers RC. Targeting coagulation activation 
in severe COVID-19 pneumonia: lessons from bacterial pneumonia and sepsis. Eur Respir Rev [Internet]. 2020 Oct 1 [cited 2021 Apr 21];29(157):200240. Available at: https://doi.org/ 10.1183/16000617.0240-2020

23. Machado C. Early prevention of hypoxemia. 2020 Nov 26. Comment on: Kim P, Read SW, Fauci AS. Therapy for early COVID-19: a critical need. JAMA [Internet]. 2020 Nov 2020 [cited 2021 Apr 21]. Available at: https://doi.org/ 10.1001/jama.2020.22813

24. Zhang R, Wu Y, Zhao M, Liu C, Zhou L, Shen S, et al. Role of HIF-1 alpha in the regulation ACE and ACE2 expression in hypoxic human pulmonary artery smooth muscle cells. Am J Physiol Lung Cell Mol Physiol. 2009 Oct;297(4):L631-40.

25. Habashi NM, Camporota L, Gatto LA, Nieman G. Functional pathophysiology of SARS-CoV-2 induced acute injury and clinical implications. J Appl Physiol. 2021 Mar 1;130(3):877-91. Available at: https://doi.org/10.1152/japplphysiol.00742.2020

26. Wang X, Tu Y, Huang B, Li Y, Li Y, Zhang S, et al. Pulmonary vascular endothelial injury and acute pulmonary hypertension caused by COVID-19: the fundamental cause of refractory hypoxemia? Cardiovasc Diagn Ther. 2020 Aug;10(4):892-7.

27. Zhang J, Tecson KM, McCullough PA. Endothelial dysfunction contributes to COVID-19-associated vascular inflammation and coagulopathy. Rev Cardiovasc Med. 2020 Sep 30;21(3):315-19.

28. Dandel M. Pathophysiology of COVID-19-associated acute respiratory distress syndrome. Lancet Respir Med [Internet]. 2021 Jan [cited 2021 Apr 23];9(1):e4. Available at: https://www.ncbi.nlm .nih.gov/pmc/articles/PMC7837097/

29. Tan DX, Hardeland R. Targeting host defense system and rescuing compromised mitochondria to increase tolerance against pathogens by melatonin may impact outcome of deadly virus infection pertinent to COVID-19. Molecules [Internet]. 2020 Sep 25 [cited 2021 Apr 21];25(19):4410. Available at: https://doi.org/10.3390/molecules 25194410

30. Cellina M, Gibelli D, Valenti Pittino C, Toluian T, Marino P, Oliva G. Risk factors of fatal outcome in patients with COVID-19 pneumonia. Disaster Med Public Health Prep. 2020 Sep 10;1-8. DOI: 10.1017/dmp.2020.346

31. Alraddadi BM, Qushmaq I, Al-Hameed FM, Mandourah Y, Almekhlafi GA, Jose J, et al. Noninvasive ventilation in critically ill patients with the Middle East respiratory syndrome. Influenza Other Respir Viruses. 2019 Jul;13(4):382-90.

32. Matthay MA, Thompson BT, Ware LB. The Berlin definition of acute respiratory distress syndrome: should patients receiving high-flow nasal oxygen be included? Lancet Respir Med. 2021 Apr 26. DOI: 10.1016/S2213-2600(21)00105-3

33. COVID-19 rapid guideline: Community-based care of patients with chronic obstructive pulmonary disease (COPD) [Internet]. London: National Institute for Health and Care Excellence (UK); 2020 Apr 9 [cited 2021 Apr 21]. 13 p. Available at: https://www.ncbi.nlm.nih.gov/books/NBK 566605/pdf/Bookshelf_NBK566605.pdf

34. Whittle JS, Pavlov I, Sacchetti AD, Atwood C Rosenberg MS. Respiratory support for adult patients with COVID-19. J Am Coll Emerg Physicians Open. 2020 Apr;1(2):95-101. https://doi .org/10.1002/emp2.12071.

35. Alqahtani JS, Mendes RG, Aldhahir A, Rowley D, AlAhmari MD, Ntoumenopoulos G, et al. Global current practices of ventilatory support management in COVID-19 patients: an international survey. J Multidiscip Healthc. 2020 Nov 18:13:1635-48.

36. Alviset S, Riller Q, Aboab J, Dilworth K, Billy PA, Lombardi Y, et al. Continuous Positive Airway Pressure (CPAP) face-mask ventilation is an easy and cheap option to manage a massive influx of patients presenting acute respiratory failure during the SARS-CoV-2 outbreak: a retrospective cohort study. PLoS One. 2020 Oct 14;15(10):e0240645.

37. Brusasco C, Corradi F, Di Domenico A, Raggi F, Timossi G, Santori G, et al. Continuous positive airway pressure in Covid-19 patients with moderate-to-severe respiratory failure. Eur Respir J. 2021 Feb 17:57(2):2002524. DOI: 10.1183/13993003.02524-2020

38. Arina P, Baso B, Moro V, Patel H, Ambler G; UCL Critical Care COVID-19 Research Group. Discriminating between CPAP success and failure in COVID-19 patients with severe respiratory failure. Intensive Care Med. 2021 Feb;47(2):237-9.

39. Perkins GD, Couper K, Connolly B, Baillie JK, Bradley JM, Dark P, et al. RECOVERY- Respiratory support: respiratory strategies for patients with suspected or proven COVID-19 respiratory failure; Continuous Positive Airway Pressure, High-flow Nasal Oxygen, and standard care: a structured summary of a study protocol for a randomised controlled trial. Trials [Internet]. 2020 Jul 29 [cited 2021 Apr 23];21(1):687. Available at: https://www.ncbi.nlm.nih.gov/pmc/articles/PMC 7388424/

40. Amirfarzan $\mathrm{H}$, Cereda $\mathrm{M}$, Gaulton TG, Leissner $K B$, Cortegiani A, Schumann R, et al. Use of Helmet CPAP in COVID-19 - A practical review. Pulmonology [Internet]. 2021 Feb 1 [cited 2021
Apr 21]. Available at: https://doi.org/10.1016/j .pulmoe.2021.01.008

41. Simonds $A K$, Hanak $A$, Chatwin $M$, Morrell MJ, Hall A, Parker $\mathrm{KH}$, et al. Evaluation of droplet dispersion during non-invasive ventilation, oxygen therapy, nebuliser treatment and chest physiotherapy in clinical practice: implications for management of pandemic influenza and other airborne infections. Health Technol Assess. 2010 Oct;14(46):131-72.

42. Favero $R$, Volpato $A$, Francesco $M$, Fiore $A D$, Guazzo R, Favero L. Accuracy of 3D digital modeling of dental arches. Dental Press J Orthod. 2019 Jan-Feb;24(1):38e31-37e37.

43. Pons-Òdena M, Valls A, Grifols J, Farré R, Cambra Lasosa FJ, Rubin BK. COVID-19 and respiratory support devices. Paediatr Respir Rev. 2020 Sep;35:61-3.

44. Walker J, Dolly S, Ng L, Prior-Ong M, Sabapathy $\mathrm{K}$. The role of CPAP as a potential bridge to invasive ventilation and as a ceiling-of-care for patients hospitalized with Covid-19-An observational study. PLoS One. 2020 Dec 31;15(12):e0244857. DOI: 10.1371/journal.pone .0244857

\section{THE AUTHORS}

Calixto Machado-Curbelo (Corresponding author: braind@infomed.sld.cu), neurologist and clinical neurophysiologist with a doctorate in medical sciences. Senior professor and researcher in neurology and clinical neurophysiology, Department of Clinical Neurophysiology, Institute of Neurology and Neurosurgery (INN), Havana, Cuba. https://orcid.org/0000-0002-05 $39-5844$

Alina González-Quevedo, physician specializing in clinical neurochemistry with a doctorate in medical sciences. Full professor and senior researcher, Department of Neurobiology, INN, Havana, Cuba. https://orcid.org/0000-0003-1952-4704

Submitted: February 26, 2021

Approved for publication: July 5, 2021

Disclosures: None 